\title{
De la contribución directa proporcional a la capitación en la Hispanoamérica republicana: Los límites impuestos por la constitución fiscal
}

\section{From Proportional Direct Contributions to the Capitation Tax in Republican Hispanic America}

\author{
Aaron Pollack ${ }^{1}$ \\ Centro de Investigaciones y Estudios Superiores en \\ Antropología Social (CIESAS)-Sureste, Chiapas, (México)
}

Recibido: 10-04-16

Aprobado: 18-07-16

\section{Resumen}

A través de una revisión bibliográfica extensiva y la consultación de fuentes primarias complementarias, este artículo analiza las variaciones en los intentos que realizaron los primeros Estados postcoloniales en Hispanoamérica para establecer contribuciones directas proporcionales y cómo las diferentes constituciones fiscales tendieron a debilitar o desmantelarlas. En las regiones con una presencia indígena demográficamente predominante, los diferentes grupos sociales, influidos por sus diversas experiencias como miembros de los estamentos coloniales, rechazaron los impuestos proporcionales, que en poco tiempo se volvieron capitaciones aplicadas principalmente a las poblaciones indígenas, o indígenas y campesinas. A la vez que reproducían, en grande medida, las dinámicas asociadas con el tributo de indios que la monarquía española había cobrado, las nuevas capitaciones influyeron en modificar las categorizaciones sociales (étnicas) del siglo XIX.

Palabras-clave: Hispanoamérica, Contribuciones directas, Capitación, Siglo XIX, Etnicidad.

\footnotetext{
1(aapollack@gmail.com ). Profesor-Investigador, Centro de Investigaciones y Estudios Superiores en Antropología Social (CIESAS) - Sureste.
} 


\begin{abstract}
Through an extensive literature review and the consultation of complementary primary sources, this article analyzes the variety in the attempts undertaken by early postcolonial states and provinces in Hispanic America to establish proportional direct taxes and how different fiscal constitutions tended to weaken or dismantle them. In those regions demographically dominated by indigenous populations, different social groups, influenced by their experiences as members of the different estates of the colonial order, rejected the proportional charges, which quickly became head taxes that were primarily applied to the indigenous, or indigenous and peasant, populations. Even as they largely reproduced the Indian tribute that had been paid to the Spanish Monarchy, the new head taxes affected the modifications of the social (ethnic) categories that took place in the nineteenth century.
\end{abstract}

Key-words: Hispanic America, Direct Contributions, Capitation, Nineteenth Century, Ethnicity.

\title{
Introducción
}

Considerar conjuntamente las historias fiscales y sociales de las sociedades hispanoamericanas en las décadas después de las independencias de la monarquía española, permite entender cómo los diferentes idearios sociales de la época se enfrentaron con la economía moral de la fiscalidad, la que se conoce como la constitución fiscal. La noción de la constitución fiscal resale a 1980 cuando Brennan y Buchanan aplicaron a la fiscalidad la idea de constitución, entendida como las reglas (leyes, reglamentos, pero también acuerdos no escritos), desarrolladas en las sociedades para delimitar los poderes del Estado (Brennan y Buchanan 2000). En el planteamiento de estos autores, la constitución fiscal refiere a las reglas que las sociedades imponen sobre el Estado (en particular sobre los funcionarios y políticos) en relación a las políticas fiscales (Brennan y Buchanan 2000). Surgido con la ola de teorías neoliberales que buscaba redefinir el papel del Estado en el siglo XX, el término constitución fiscal ha sido retomado por varios historiadores que han reconocido su utilidad a la vez que se han distanciado de la manera que Brennan y Buchanan lo aplicaron.

En su interpretación del término, Daunton (2001: 8) rechaza una visión dicotómica que divide el Estado del resto de la sociedad, y refiere que la "constitución fiscal' puede tomarse como un hecho, estableciendo los parámetros dentro de los cuales las disputas ocurren”, pero "en algún momento [...] se vuelve un asunto de disputa, cuando las reglas del juego se renegocien y los límites máximos de la imposición fiscal se suban o se 
bajen"2. Alonso García (2003: 273), a diferencia de Brennan y Buchanan, considera "que los límites al poder no deban venir necesariamente desde la rebaja impositiva", y en su estudio sobre la Villa de Madrid en los tiempos de Carlos V, demuestra cómo la oligarquía madrileña podía beneficiarse de aumentos en la exacción fiscal y otros sectores de la ciudad aprovechaban del mayor gasto municipal que el acuerdo entre la oligarquía y el rey permitió. Todo lo cual, según Alonso, repercutía en que Carlos tuviera "asegurada la fidelidad y gobernabilidad de un territorio de enormes recursos" (Alonso 2003: 291).

La propuesta de Brennan y Buchanan fue explícitamente reelaborado por Richard Bonney (1995b: 6-7 y 1995c: 431-438) para considerar cómo los diferentes actores de la sociedad moderna temprana actuaban, a través de su participación en las cortes u otros cuerpos similares, las protestas y las rebeliones para delimitar el alcance de las políticas fiscales. Bonney se dirigió hacia entender cómo la fiscalidad se desarrollaba en Europa en la temprana modernidad (Bonney 1995a) y, al reconocer la importancia en este proceso de los muchos sectores que no fácilmente se describen como sectores dominantes, convierte la constitución fiscal en concepto clave para combinar las historias fiscal y social ${ }^{3}$.

Vinculada muy cercanamente con las ideas de la ciudadanía universal y la conversión de propiedad colectiva en propiedad privada, la contribución directa ${ }^{4}$, entendida entonces como un impuesto, de preferencia proporcional, sobre los ingresos y/o las riquezas del individuo, fue propuesta casi universalmente en Hispanoamérica en la tercera década del siglo XIX y se mantuvo, en la práctica o en el debate público y gubernamental, en las siguientes. En el transcurso de pocos años, la contribución directa se redujo, en las regiones con poblaciones indígenas significativas, a pagos de relativamente poca importancia realizados por los grupos pudientes, y una capitación aplicada a los indígenas (o indígenas y campesinos) que asemejaba al tributo de indios, eliminado apenas unos años atrás. Por ser, en grande medida, las herederas del tributo, las capitaciones mantuvieron vivas, aun mientras modificaban, las distinciones estamentales basadas en criterios "étnicos" de la época colonial, por lo que su análisis permite unas consideraciones iniciales sobre la relativa importancia de lo fiscal en algunas de las distinciones "étnicas" de la época.

\footnotetext{
2 Traducción del autor.

${ }^{3}$ Otros autores, como Alonso (2003), O’Brien (2011) y Etchechury (2013) -quien lo ha equiparado con el pacto fiscal- han utilizado el término constitución fiscal para referirse principalmente a los arreglos que los sectores poderosos de una sociedad negocian para crear o mantener un sistema fiscal que permite el funcionamiento de un Estado - y en el caso de Alonso también de la Villa de Madridque efectivamente se desarrolla principalmente para cumplir con sus intereses. Véase también Storrs (2009).

${ }^{4}$ En general, el término "contribución directa" refiere a un impuesto aplicado a una persona o una empresa y se difiere de una "contribución indirecta" que se cobra sobre los bienes y servicios, pero es de subrayarse que estas categorías se entendieron de manera particular durante los siglos XVIII y XIX y que su definición podía variar (Guery 1986: 1048-1049; Jáuregui 2006a: 9-21).
} 
El estudio de las capitaciones y contribuciones directas cobradas como capitaciones se ha abordado principalmente desde dos grandes subdisciplinas de la Historia. La historia social ha enfocado especialmente en cómo este impuesto se insertaba en los demás procesos que influyeron en la vida de los pueblos indígenas a lo largo del siglo XIX: la privatización de la tierra; las relaciones laborales; y las modificaciones en los vínculos entre las personas, las comunidades y las estructuras gubernativas ${ }^{5}$. Más reciente, otros investigadores se han acercado a estos mismos temas con una visión poscolonial que ha buscado captar cómo las sociedades republicanas reprodujeron y modificaron las relaciones sociales -particularmente aquellas entre los diferentes grupos étnicos- a lo largo del siglo XIX ${ }^{6}$.

Desde un enfoque que parte de los nuevos Estados y sus esfuerzos por asegurar las bases económicas que permitirían su funcionamiento, los historiadores fiscales han visto a las capitaciones dentro del panorama de los diferentes impuestos aplicados en este periodo, en el que, más recientemente, han enfatizado particularmente las contribuciones directas ${ }^{7}$. En la última década, Juan Carlos Garavaglia y el equipo del proyecto State Building in Latin América, han analizado las cuestiones fiscales como uno de varios aspectos fundamentales para la formación de los Estados en Latinoamérica y han analizado las contribuciones directas (y a veces las capitaciones) en sus trabajos $^{8}$. Otro acercamiento reciente, derivado de la nueva historia política, es la propuesta de Marta Irurozqui que analiza cómo las nuevas nociones que justificaron la capitación republicana en Bolivia modificaron,-en el pensamiento de los gobernantes y los pueblos- las ideas pactistas que consideraban al tributo como muestra de vasallaje entre la monarquía española y sus súbditos?

En un esfuerzo por interrelacionar e interpelar los diferentes enfoques mencionados, en este artículo analizo las capitaciones republicanas (con énfasis particular en los primeros años de su implementación) y su vínculo con otras contribuciones directas, alrededor de dos ejes principales. Por un lado considero las ideas de la progresividad impositiva y de la exención fiscal para las personas con menores ingresos: dos ideas que se relacionan con una visión de equidad. Por el otro, reflexiono sobre cómo los diferentes sectores

5 Sánchez Albornoz (1978); Van Aken (1981); Platt (1982); Hünefeldt (1989, 1991); Palomeque (1991); Bonilla (1991, 1997); Méndez (1997); Peralta (1991, 1997); Klein (1995); Guarisco (1995, 2003); Sánchez Silva (1998: 113-124); Contreras (1989) Bushnell (1999), Güémez (2005); Escobar (2010); Ortiz Yam (2015).

6 Thurner (1997), Guerrero (2002, 2010).

7 Lofstrom (1970, 1972); Jacobsen (1989); Coría (1998); Ibarra (1998, 2001); Contreras (2005); Abendroth (2006); Gelman y Santilli (2006); Jaúregui (2006a, 2006b); Serrano (2007); Pinto (2012); Sánchez Santiró (2012); Hernández (2013: 113-117; 251-255); Moreno (2014).

${ }^{8}$ Garavaglia (2010); Sarazúa (2012); Etchechury (2013); Rodríguez Solano (2013); López Taverne (2014)

${ }^{9}$ Irurozqui (1999, 2006). El trabajo fundamental de Morelli (2005: 169-190) es otro aporte de la nueva historia política.

Araucaria. Revista Iberoamericana de Filosofía, Política y Humanidades, año 18, n 36 . Segundo semestre de 2016. Pp. 59-86. ISSN 1575-6823 e-ISSN 2340-2199 doi: 10.12795/araucaria.2016.i36.04 
respondieron a las nuevas políticas fiscales y cómo las constituciones fiscales influyeron en las formas impositivas que los nuevos Estados aplicaron.

\section{Antecedentes}

Como sujetos de la monarquía española, los diferentes sectores de las sociedades hispanoamericanas experimentaron contribuciones directas similares a los del siglo XIX con el diezmo (finalmente un impuesto directo proporcional sobre el ingreso) y el tributo. Al independizarse, los nuevos Estados hispanoamericanos retomaron estas experiencias en la elaboración de las nuevas contribuciones directas que para entonces se habían discutido ampliamente en Europa.

Las contribuciones directas proporcionales tenían antecedentes en los impuestos franceses del siglo XVIII (capitation, dixième y vingtième) y -de alguna manera- en los impuestos sobre la tierra (land tax) que se habían implementado en Inglaterra, aunque en los dos casos la efectividad de la aplicación de la proporcionalidad se debilitó con la resistencia de los sectores pudientes (Gross 1993; O’Brien 2011). Los intentos al interior de la monarquía española por aplicar una contribución única durante la segunda mitad del siglo XVIII habían fallado y solamente con la crisis de la monarquía pudo aplicarse una contribución directa universal (y de manera muy limitada) por decisión de las cortes gaditanas. No obstante estos antecedentes, en la tercera década del siglo XIX, cuando los gobiernos hispanoamericanos comenzaron a legislar y aplicar estas iniciativas, las nuevas contribuciones no eran de común aplicación en Europa, en parte por considerarse vinculadas con el radicalismo de la revolución francesa y, seguramente, por el clima general de la Restauración en Europa.

Además de los impuestos directos mencionados, puede percibirse que las contribuciones directas implementadas por los nuevos estados hispanoamericanos también tenían antecedentes en el pensamiento francés de la segunda mitad del siglo XVIII en torno a los impuestos directos progresivos y en sus aplicaciones en las décadas posteriores por los revolucionarios franceses y sus seguidores en Holanda, por sus contrarios en el Reino Unido y, más de cerca, por las cortes gaditanas (Bonney 1995: 485-487; López Castellano 1995). El pensamiento tras los impuestos progresivos suponía que, además de asegurarle ingresos al Estado, los sistemas impositivos debían buscar distribuir las cargas fiscales de manera más equitativa y por consiguiente se contemplaría una exención para contribuyentes cuyos ingresos o riqueza no sobrepasaban cierto umbral.

La importancia de la progresividad en lo fiscal en Hispanoamérica resultó mínima durante la primera mitad del siglo XIX, más allá de la contribución 
"directa general y extraordinaria" decretada por el virrey Calleja en la Nueva España en $1813^{10}$ y las propuestas -nunca aplicadas- de Santiago Wilde, miembro de la Comisión de Hacienda de la Sala de Representantes en la provincia de Buenos Aires en 1821 (Sánchez Santiró 2012; Gelman y Santilli 2006: 495-496).

Desde el momento de consolidar su independencia, los nuevos Estados hispanoamericanos -en general muy influidos por las ideas asociadas con el liberalismo y el republicanismo de la época-, casi de manera uniforme, legislaron contribuciones directas ${ }^{11}$ que buscaban gravar la riqueza y/o los ingresos del individuo o bien delegaban esta posibilidad a los territorios (estados o departamentos) ${ }^{12}$ que conformaban los nuevos países. Estas contribuciones no buscaban la progresividad, pero sí preveían -como parte de los esfuerzos por establecer una relación directa entre el Estado y cada individuo- un cobro proporcional que se aplicara universalmente a todos los habitantes masculinos (y a veces a algunas mujeres) sin excepciones y sin diferencias regionales (Serrano 2007). El criterio de la proporcionalidad se había aplicado en diferentes momentos y lugares históricos ${ }^{13}$, pero plantear la uniformidad territorial y la eliminación de los fueros que exceptuaban a ciertos grupos (como el clero) en un territorio amplio era todavía una relativa novedad ${ }^{14}$. La mayor parte de las contribuciones directas en Hispanoamérica enfrentó una resistencia -variada según la región- que no permitió su aplicación en los términos universalistas que sus proponentes habían deseado.

Los diferentes rubros que podían estar presentes en las nuevas contribuciones directas (Jáuregui 2006a: 20-21), incluían los impuestos sobre el ingreso (la renta), a veces cobrados a través de los "patentes" (pago fijos que se asignaban de manera diferenciada a las distintas ocupaciones), y a veces tasados como un porcentaje de los ingresos anuales declarados. Asimismo, en algunas contribuciones se designaba el pago anual de un porcentaje de la

${ }^{10}$ La contribución "directa general y extraordinaria" novohispana puede considerarse progresiva sólo en referencia a las capas sociales con ingresos más bajos pues dejó de ser progresiva para las capas más altas (Sánchez Santiró 2012: 17-18).

11 Jáuregui ofrece una importante discusión sobre la contribución directa y su aplicación en Hispanoamérica durante el siglo XIX en la introducción de un importante libro que contempla varios estudios de caso en la región (Jáuregui 2006a, 2006b). Asimismo, Serrano aporta una discusión amplia sobre la aplicación de estos nuevos impuestos en México durante la primera república federal y el centralismo (Serrano 2007).

${ }^{12}$ La cuestión tomó importancia especial en México, por tratar un tema de la división de las facultades fiscales entre el gobierno federal (o central) y los estados (o departamentos) (Serrano 2007:163167; Hernández 2013: 251-255). Asimismo, resultó relevante en Perú, donde algunos departamentos dependieron exclusivamente de la capitación para sus ingresos que, en un contexto de guerra, podían dar mucha autonomía a los funcionarios departamentales (Bonilla 1991: 343; Peralta 1991: 41, 48).

${ }_{13}$ Los impuestos graduados o progresivos se habían aplicado en algunas regiones europeas desde el siglo XV (Seligman 1894; Gross 1993; Bonney 1995: 484-488).

${ }^{14}$ La capitation, dixième y vingtième aplicadas en Francia a partir de finales del siglo XVII y durante el XVIII debían aplicarse a todos los sujetos, pero el clero compraba una exención y posteriormente debió realizar "regalos voluntarios" para mantenerla (Kwass 1998: 323, n. 59). 
riqueza, generalmente calculada sobre las "fincas rústicas" y "fincas urbanas". En algunas ocasiones se cobraban impuestos sobre ciertos lujos (carruajes, caballos de montar, un determinado número de sirvientes, etc.) que, en la ausencia de un catastro, permitían suponer un nivel aproximado de riqueza ${ }^{15}$.

Entre las categorías de empleo que se alistaban para el pago del impuesto sobre el ingreso, podían aparecer las de "jornalero" o "sirviente" y, a veces, la de "indígena". Asimismo, otro tipo de contribución directa era la capitación, que constaba de una cantidad uniforme cobrada a todos los hombres entre ciertas edades ${ }^{16}$. La capitación podía legislarse -como veremos en seguidadentro de conjuntos más amplios de contribuciones directas que gravaban a los ingresos, a la riqueza o a los dos; podía también aplicarse por sí solo, sin otra contribución directa. En la práctica, una capitación general se distinguía de la contribución cobrada a un jornalero, sirviente o indígena por su "ocupación" en la medida que los otros sectores de la sociedad la pagaba. Para los indígenas y algunas castas que habían pagado el tributo hasta poco tiempo antes, el nuevo cobro republicano debió asemejarse mucho a la antigua demostración de vasallaje.

En los nuevos Estados, o en algunas de sus provincias en las que la presencia indígena era significativa, las capitaciones o contribuciones aplicadas a los campesinos o indígenas (a las que de aquí en adelante referiré como “capitaciones") resultaban ser partes considerables de los ingresos fiscales. En la mayoría de estos casos, la relativa importancia de las capitaciones correspondía a la que el tributo de indios y castas había tenido en el periodo colonial ${ }^{17}$, lo que exigió que el sistema estamental colonial se mantuviera en grande medida ${ }^{18}$, aun cuando las diferentes maneras en que estos impuestos se aplicaron también reflejaban -y promovían- las variadas modificaciones en ese sistema que se darían a lo largo del siglo XIX, especialmente el fortalecimiento, en algunos casos, de una convergencia entre los grupos no indígenas en una sola categoría y la creación de un binomio "indígena -no indígena" (Taracena Arriola et al. 2002). Las capitaciones y los otros cobros fiscales en estos territorios formaban solo un aspecto de las acciones, oficiales y no oficiales, que favorecían la creación de la categoría social "indígena" (heredera del "indio" colonial), cuya existencia obviamente suponía la de otra(s) categoría(s) social(es).

${ }^{15}$ Este tipo de impuestos se derivó, en parte, del pensamiento que subyacía en los gravámenes sobre bienes suntuarios, como los cobrados sobre mercancías (excise taxes), consideradas "de lujo" o "superfluas" en el sistema británico del siglo XVIII (O’Brien 1988: 12-13) y propuestos en Francia durante la segunda mitad del mismo (Gross 1993: 18, 102).

${ }^{16}$ En general, no se modificaban de manera importante las edades utilizadas durante la colonia para los tributos de indios, es decir, aproximadamente entre los 16 y los 50 años.

17 Debido a una disminución notable en los ingresos provenientes de la minería en los años cercanos de la independencia, la capitación boliviana aportó un porcentaje mayor del que el tributo de indios había abonado en la Audiencia de Charcas (Klein 1995:144).

${ }^{18}$ Véase Pollack (2016) para unas consideraciones sobre la relación entre el sistema estamental y los tributos de indios y castas en Hispanoamérica. 
Claramente, además de la capitación, había otros impuestos de mucha importancia que se cobraban en Hispanoamérica en este periodo y la mayoría de ellos, como la capitación misma, eran de herencia colonial: las alcabalas internas y externas, los estancos -particularmente los de licores y de tabacoy los diezmos (claramente similares a los impuestos territoriales o sobre la propiedad que a veces formaban parte de las contribuciones directas). Estos gravámenes podían aplicarse a todos los sectores de la población, aunque en algunos casos seguía vigente el debate -abierto desde del siglo XVIII (Menegus 1998) - sobre si les correspondía a los indígenas pagarlos y si el cobro de la capitación de alguna manera les debía exentar de estos cobros, lo que resultó ser lo más común en la práctica ${ }^{19}$.

\section{Variaciones sobre un tema. Impulsos iniciales}

Resulta interesante considerar los intentos casi uniformes entre los nuevos países hispanoamericanos por implementar una contribución directa, aplicada a los individuos o los bienes, de manera proporcional y (casi) universal. El trayecto desde el afán por asegurar una distribución más equitativa de la carga fiscal a la dependencia - en muchos casos- de la capitación, ha sido objeto de análisis y en este artículo espero construir sobre lo que ya se ha avanzado ${ }^{20}$. Asimismo, es notable la variación entre los planteamientos iniciales de los diferentes gobiernos en torno a estas contribuciones y las diferentes maneras en que la capitación se aplicaba como un aspecto de ellas.

En el Congreso de Cúcuta de 1821, la "Gran Colombia"²1 de Bolívar aprobó una contribución directa sobre las rentas o ganancias similar a la implementada en el estado mexicano de Jalisco en 1825 y a la contribución forzosa de guerra que el Congreso Constituyente Yucateco intentó aplicar durante los primeros meses de 1824. Las contribuciones aplicadas en las provincias rioplatenses de Buenos Aires (1822) y Mendoza (1825) cobraban un porcentaje, variable según el tipo de capital en el primer caso, sobre los capitales asentados ${ }^{22}$. En Uruguay,

19 Entre los legisladores de la época, era común el planteamiento que los indígenas no pagaban alcabala porque tenían poca necesidad de realizar compras sujetas a este gravamen, lo que hacía necesaria la capitación, como única manera de asegurar su aportación fiscal. De hecho, Irurozqui ha argumentado la importancia de la capitación -en la visión republicana de los gobernantes bolivianos del sigo XIX- como un mecanismo a través del cual los indígenas cumplieran con "uno de los deberes cívicos básicos, el del contribuyente [...] y [...] como una oportunidad para los indígenas de reinventarse como servidores del Estado y ganar así el estatus de ciudadano" (Irurozqui 2006: 48).

${ }^{20}$ Para otros intentos comparativos a nivel hispanoamericano, pueden verse Sánchez Albornoz (1978: 186-204); Bonilla (1997); Jáuregui (2006b) y Escobar (2010).

${ }^{21}$ El nombre "Gran Colombia" ha resultado de utilidad para referir a la unión política, durante la tercera década del siglo XIX, de los territorios que posteriormente formarían Venezuela, Colombia, Ecuador y Panamá.

22 Sobre la Gran Colombia, véase Pinto (2012: 58-59); sobre Buenos Aires, Gelman y Santilli 
en 1827, la Comisión de Hacienda, como lo habían hecho algunos publicistas y consejeros del gobierno con anterioridad, propuso una contribución que se basaba en la que se aplicaba en Buenos Aires, aunque la iniciativa nunca prosperó (Etchechury 2013: 154) ${ }^{23}$. La contribución personal que se aprobó e implementó en el estado de Oaxaca en 1824 gravaba la propiedad y los ingresos ${ }^{24}$.

La ley centroamericana de 1823 contemplaba tarifas anuales correspondientes a diferentes "clases" y el pago de un porcentaje de los sueldos y beneficios, sin considerar una capitación denominada como tal, aunque sí indicaba un cobro para jornaleros, sirvientes domésticos e "indígenas no propietarios" $" 25$. El modelo centroamericano se reprodujo en la contribución directa implementada en el estado de Guatemala en 1825 (Sarazúa 2012: 7679) y el establecimiento de una contribución directa en el estado del Salvador, en agosto de 1832 que se abolió apenas cuatro meses después ante las revueltas que generó (Herrera 2008: 111-112) ${ }^{26}$.

A diferencia de la ley centroamericana sobre contribuciones, las decretadas por el Imperio Mexicano (1822) y Bolivia (1825) hacían referencia a una contribución directa que contemplaba una capitación universalmente aplicable, además de cobros sobre la propiedad (en el primer caso) y sobre la propiedad, la renta y los salarios (en el segundo) ${ }^{27}$. Después de la caída del Imperio, el Congreso Constituyente de México aprobó otra contribución directa que contemplaba que cada persona -hombre o mujer- que tuviera ingreso, debía pagar anualmente un impuesto igual al valor de tres días de salario (Serrano 2007: 53-54; Hernández 2013:127-128). En el estado mexicano de Jalisco,

(2006: 496); sobre Mendoza, Coria (1998); sobre Yucatán, Moreno (2014: 35-38) y sobre Jalisco, Ibarra (1998).

${ }^{23}$ Se discutió la posibilidad de legislar una contribución directa otra vez en Uruguay en 1831 (Etchechury 2013: 299). Las élites chilenas rechazaron las iniciativas para las contribuciones directas propuestas durante la tercera década del siglo XIX (López Taverne 2014).

${ }^{24}$ La contribución personal en Oaxaca reemplazó la capitación que la diputación provincial de Oaxaca había implementado en 1822 (Sánchez Silva 2012: 294, n. 10).

${ }_{25}$ Ordenanza para la recaudación, administración y reparación de agravios del impuesto general, decretado en primero de diciembre de 1823, 22 de enero de 1824, Archivo General de Centroamérica (AGCA), Signatura B, Legajo 4125, Expediente 92803. Agradezco a Juan Carlos Sarazúa por facilitarme el acceso a este documento. Asimismo, el decreto registraba un cobro específico para "los indígenas propietarios según las clases de bienes que gozaren" (Sarazúa 2013: 80).

${ }^{26}$ En la "tarifa" correspondiente a la contribución del estado de Guatemala de 1825, se refiere a la categoría de "indígenas de 18 a 50 años" como también a las de "jornaleros de 18 a 50 años" y "sirvientes domésticos" (Sarazúa 2012: 78). En la del estado de Salvador, se refiere al rubro de "jornaleros indígenas no propietarios y sirvientes domésticos" (Decreto sobre contribución directa: 75). En Costa Rica hubo varios intentos por establecer una contribución directa, pero en general terminaron destinados a financiar la construcción o mantenimiento de caminos (Rodríguez 2013: 245246 n. 616, 318-319). Marure (1844: 24) refiere al establecimiento de una "única contribución" en el estado de Honduras en 1831 y Barahona (1995: 27) menciona una capitación de diez reales anuales cobrada en el mismo territorio en 1838.

${ }^{27}$ Sobre Bolivia, véase Lofstrom (1970: 282-83) y Barragán (2012: 23-24); y sobre México, Tenenbaum (1998: 221-222) y Hernández (2013: 113-117). 
se cobró una contribución directa graduada para contribuyentes con ingresos anuales mayores de 200 pesos, mientras que a los que tuvieron ingresos menores se les cobraba una capitación (Ibarra, 2001: 338). De manera similar, en Perú se decretó una ley de contribuciones directas en 1826 que contemplaba las capitaciones denominadas "contribución de indígenas" y "contribución de castas" 28 , además de contribuciones sobre predios urbanos y rústicos, el cobro de patentes y una contribución de industrias. La relación entre los distintos cobros se volvió compleja en Perú, pero con el tiempo, resultaba que si el individuo tenía ingresos mayores de un determinado nivel mínimo, le correspondía pagar los patentes o la contribución de industria, y entonces era eximido de las contribuciones "de indígenas" y "de castas" (Hünefeldt 1989: 371-372; Jacobsen 1989: 323-330; Contreras 2005: 80-81).

El caso de los Departamentos del Sur (conformados por la antigua audiencia de Quito o sea el actual Ecuador) es particular porque, no obstante la eliminación inicial, en 1821, del tributo en toda la Gran Colombia y el establecimiento de la contribución directa mencionada arriba en el mismo año, las necesidades militares empujaron a que el propio Bolívar restableciera el tributo y lo mantuviera hasta el fin de la guerra en 1825. En 1826, tanto en los Departamentos del Sur como en el resto de la Gran Colombia, se abolió la contribución decretada en Cúcuta y se aplicó una capitación universal a todos los habitantes masculinos, que encontró resistencia y terminó eliminándose a favor de una "contribución personal de indígenas" que Bolívar implementó en 1828 (Morelli 2005: 176-180).

En el estado mexicano de Chiapas, como excepción al ímpetu inicial hacia la proporcionalidad en el cobro de los impuestos, el 1 de marzo de 1824, unos veinte días antes de convocar los partidos a decidir la posible adhesión del territorio a México o Centroamérica, la Junta Provisional decretó una capitación universal de un real por mes, aplicable a todos los hombres adultos (Trens 1999: 258). Para subrayar la importancia que tenía la cuestión fiscal en ese momento, en la convocatoria para el voto mencionado, se indica "nadie mejor que ellos, sobre quienes ha de gravitar el día de mañana el peso de las contribuciones directas o indirectas, podrá acertar en la elección a la nación a que se federen" (Trens 1999: 258) ${ }^{29}$. En el Estado de México, un territorio enorme que para entonces se extendía hasta la costa del Pacífico (e incluía una

${ }^{28}$ Contreras (2005: 84 Cuadro 3, 71) indica que en 1815, cuando Fernando VII restableció el tributo, bajo el nombre de "contribución", el virrey Abascal amplió el cobro a las castas. La capitación cobrada entre 1840 y 1852 en la provincia de Jujuy, que había formado parte de la provincia rioplatense de Salta hasta 1834, se asemejaba a la "contribución de indígenas" peruana en cuanto se cobraba solamente a los indígenas, pero era única en el sentido de que se estableció como mecanismo para que los que querían, pudieran eximirse de la participación en las milicias (Bushnell 1999: 592-598).

${ }^{29}$ Citado en Torres (2014: 152). En este momento, las federaciones centroamericana y mexicana cobraban contribuciones directas, aunque con poco éxito (Sarazúa 2013: 56; Hernández 2013: 128, 130 Cuadro III.1 y 158). 
buena parte de lo que actualmente es el estado de Guerrero), en 1827 se legisló una contribución directa aplicable a los hombres que los ayuntamientos debían cobrar e invertir en la educación pública ${ }^{30}$. Hacia 1829, esta contribución se cobraba en forma proporcional a todos los padres de familia, a quienes les correspondía una aportación de entre uno y cuatro reales (Guarisco 2003: 40).

Con este breve resumen de los primeros intentos por establecer las contribuciones directas en los nuevos Estados hispanoamericanos, podemos apreciar un interés inicial por parte de los gobiernos -o por algunos legisladores al menos- de la época por establecer sistemas fiscales en los que la carga fiscal se repartiera, en casi todos los casos, de manera proporcional. Sin embargo, resulta necesario distinguir que entre la variedad de contribuciones propuestas e implementadas, existían diferencias que atañían tanto a la geografía y la historia (y la constitución) fiscal de las diferentes regiones como también a la visión política de los gobernantes.

\section{¿Un umbral mínimo?}

A pesar de la escasa atención que se le ha prestado en las discusiones sobre Hispanoamérica, resulta reveladora la presencia o ausencia de una provisión en las leyes sobre las contribuciones que estableciera una exención para los sectores con menos ingresos. Dentro del pensamiento sobre la fiscalidad que influyó en las diferentes propuestas para los impuestos progresivos, se encontraba con frecuencia la noción de que las personas con ingresos mínimos debían ser exentas de las contribuciones a los erarios públicos, como Robespierre anotó en su propuesta - nunca aceptada- para la revisión de los Derechos del hombre y del ciudadano en 1793: “Les citoyens dont le revenu n'excède pas ce qui est nécessaire à leur substance sont dispensés de contribuer aux dépenses publiques. Les autres doivent les supporter progressivement, selon l'étendue de leur fortune" $"$.

Las iniciativas de Cúcuta (Gran Colombia) y Buenos Aires contemplaron exenciones para personas con pocos ingresos y la de Yucatán parece haberse pensado en términos de un cobro a personas con bienes cuyo valor rebasaba un cierto nivel (Pinto 2012: 59; Gelman y Santilli 2006: 496; Moreno 2014: 35-38). A diferencia de estas iniciativas, las primeras contribuciones directas

\footnotetext{
${ }^{30}$ Esta contribución se asemeja a la contribución de "Comunidades" vigente durante buena parte del periodo colonial, también utilizada para gastos relacionados con las escuelas o el mantenimiento de edificios públicos.

${ }^{31}$ Artículo 13 de la Déclaration des droits de l'homme et du citoyen, présentée par Maximilien Robespierre [imprimé par ordre de la Société des Amis de la Liberté et de l'Egalité], 24 de abril de 1793, Project Gutenberg Ebook of Discours par Maximilien Robespierre - 17 Avril 1792-27 Juillet 1794, by Maximilien Robespierre, [En línea] http://www.gutenberg.org/files/29887/29887-h/29887-h. htm\#17930424, consultado el 6 de marzo de 2016.
} 
planteadas en otras partes de América no consideraron exenciones para personas con ingresos reducidos ${ }^{32}$. La contribución directa aprobada por las Provincias Unidas del Centro de América en 1823 refirió solamente a una exención para personas impedidas de trabajar (Sarazúa 2012:76), quienes habían estado exentas también del tributo de indios a lo largo del periodo colonial; en Oaxaca, se exentaron a los impedidos y las personas en "verdadero estado de mendicidad" (Serrano 2007: 99), aunque el impuesto se había establecido con la intención de exonerar a los muy pobres (Sánchez Silva 2012: 293-294). En Bolivia, se exentaron a las personas inválidas (Lofstrom 1970: 405) mientras en las leyes posteriores en la Gran Colombia (que todavía incluía a los Departamentos del Sur), el decreto de 1826 que estableció la capitación no indicó exención alguna y el de 1828, que estableció la contribución personal de indígenas, refiere a la exención de los impedidos ${ }^{33}$. La ley peruana de 1826 no contemplaba una exención para los más pobres, sino que los de ingresos menores de cien pesos les correspondía el cobro de la capitación y no las demás contribuciones (Hünefeldt 1989: 372).

El tema de la exención a los más pobres estaba presente en las discusiones sobre las contribuciones directas, como demuestra la ley ecuatoriana de 1831-un año después de su independencia de la Gran Colombia- que, no obstante su breve vigencia de apenas unos meses, incluía un impuesto graduado sobre el ingreso, la eliminación de la capitación y una exención para todos los contribuyentes con ingresos anuales menores de cien pesos (Van Aken 1981: 444-445). También en México, la cuestión de la exención de los más pobres fue tema de mucha discusión en torno a la capitación nacional durante la década de 1840 (Serrano 2007: 140-163). En el Perú, la discusión sobre una posible exención se refería principalmente a algunas de las personas a quienes correspondería la categoría del pago de la contribución de castas: es decir personas sin acceso a la tierra, ni oficio definido y a menudo bastante móviles ${ }^{34}$. En 1839 se eliminó (por un periodo breve) la contribución de castas por considerar que recaía "sobre personas miserables cuyos recursos apenas basta[ba]n para sostener las primeras necesidades de la vida sin aliviar las del Estado"35.

${ }^{32}$ En los debates sobre la contribución directa aprobada por la Federación Mexicana en 1823, un diputado propuso la exención para todos los contribuyentes cuyos ingresos anuales no alcanzaban los cien pesos (Serrano 2007: 54).

33 "Decreto que ordena ejecutar fielmente las leyes de hacienda", 23 de noviembre de 1826; "Decreto que establece la contribución personal de indígenas", 15 de octubre de 1828.

${ }^{34}$ Es de notarse que el intento de Abascal para cobrar la capitación a las castas, retomado por las autoridades peruanas, presuponía la dificultad en cobrarles; por este motivo y dado que no tenían acceso a la tierra y debían participar en el servicio militar - se les cobraba a una tasa menor (Contreras 2005: 76). La importancia de la relación entre la participación en los cuerpos militares y la exención de la capitación no podrá abordarse en este artículo por falta de espacio.

35 Dancuart y Rodríguez (1902-26, vol. III: 102), citado en Jacobsen (1989: 327). Se nota la similitud en el lenguaje utilizado por Robespierre en la cita referida arriba. 


\section{Las contribuciones aceptadas y sus implicaciones}

Los primeros intentos por establecer una contribución directa enfrentaron diversas respuestas de los diferentes sectores sociales cuyas obligaciones fiscales cambiaban con los nuevos regímenes. No debe sorprenderse que, dada la fluidez de las categorías sociales, a veces resulta difícil identificar la actitud de los diferentes actores hacia los nuevos impuestos; esto resulta particularmente difícil al buscar distinguir los posicionamientos de los grupos más pudientes $-\mathrm{y}$ tendencialmente más cercanos al estamento colonial de "español"-y las de los grupos mestizos o castas pues en estos años la distinción entre ellos comenzó a desdibujarse ante la creación -por lo menos en algunos de los casos- de sociedades más claramente bifurcadas en indígenas y no indígenas. Asimismo, las categorías étnico-fiscales esconden mucha información sobre la situación económica al interior de cada una de ellas, lo que dificulta analizar los motivos tras las actitudes de los diferentes sectores. Efectivamente, es de suponerse que las modificaciones en las categorías fiscales tuvieron su importancia en la reelaboración de las categorías étnicas. Reconociendo estas limitaciones -y a la vez la fertilidad de lo que implican para reevaluar las categorías que retomamos de los documentos para desarrollar nuestros análisis- este apartado describe de manera breve las reacciones que los diferentes sectores sociales mostraron ante el establecimiento de las contribuciones directas y las capitaciones.

Sin muchas excepciones, se puede afirmar que los sectores más poderosos rechazaron de inmediato la aplicación de las contribuciones, en cierta medida proporcionales, sobre la renta y la riqueza o bien lograron evitarlas o minimizar sus impactos. La contribución directa que inicialmente se aplicó de manera experimental en Bolivia en 1826 enfrentó una resistencia de muchos sectores de la sociedad, entre ellos de los grupos poderosos, poco acostumbrados a pagar impuestos; algunos de sus miembros, como lo harían unos años después los "blancos-mestizos" ecuatorianos, consideraron que se trataba de convertirlos en tributarios como los indios (Lofstrom 1970: 283; Irurozqui 2006: 54). Unos seis meses después de su aplicación, resultó claro que sería difícil la sobrevivencia de la contribución directa y el siguiente año se restableció el tributo para los indígenas y, efectivamente, se eliminaron los impuestos directos para los demás sectores de la sociedad boliviana (Lofstrom 1970: 284-287) ${ }^{36}$. Aunque hubo propuestas en los años posteriores a favor de la aplicación de contribuciones directas a los otros sectores sociales, las que se aplicaron nunca tuvieron un impacto fiscal significativo (Irurozqui 2006: 58-60; Abendroth 2006: 107-110).

En Yucatán, la contribución pudo aplicarse apenas los primeros meses de 1824, antes de que la resistencia de los propietarios, los rentistas y los

\footnotetext{
36 "Los indígenas quedan sujetos a la contribución que han satisfecho hasta ahora" cita muy apropiadamente Sánchez Albornoz (1978: 192) del $2^{\circ}$ artículo del decreto del 27 de diciembre de 1827.
}

Araucaria. Revista Iberoamericana de Filosofía, Política y Humanidades, año 18, n ${ }^{\circ} 36$. Segundo semestre de 2016. Pp. 59-86. ISSN 1575-6823 e-ISSN 2340-2199 doi: 10.12795/araucaria.2016.i36.04 
comerciantes (Serrano 2007: 96-97; Moreno 2014: 38) forzara su reemplazo con una capitación aplicable a todos los yucatecos masculinos y pagable dos veces al año, en junio y diciembre, como se había cobrado el tributo de indios (Moreno 2014: 38) ${ }^{37}$. La contribución oaxaqueña, a pesar de mantener oficialmente una proporcionalidad y la universalidad, recayó principalmente sobre los indígenas, por la resistencia al cobro que mostraron los "capitalistas y propietarios" (Sánchez Silva 2012: 294; Serrano 2007: 101-102).

En los Departamentos del Sur de la Gran Colombia, las élites se inconformaron ante la pretensión, explicitada en la ley de la contribución directa de 1825 , de cobrar a los propietarios y profesionales, logrando la eliminación de este impuesto y la implementación de una capitación universal el siguiente año, la que a su vez se enfrentó con el rechazo de muchos indígenas, mestizos y blancos, llegando incluso a la insurrección (Morelli 2005: 178-179). Con la eliminación de esta capitación universal en la Gran Colombia, en 1828 se implementó la, ya mencionada, "contribución personal de los indígenas" que, no obstante los esfuerzos en la independiente (a partir de 1830) república de Ecuador por convertirla en una contribución graduada en 1831 o una capitación universal en 1835 y 1843 , se mantuvo, en contenido, aunque no en nombre, hasta 1857 (Van Aken 1981: 444-445).

Resultan interesantes las reacciones de aquellos grupos no identificados como indígenas que, en términos generales, tuvieron pocos recursos, pues las respuestas ante los gravámenes que se les quiso imponer oscilaban de la anuencia a la evasión y la resistencia abierta. En el centro y norte de la sierra ecuatoriana, la virulencia del rechazo de los "blancos-mestizos" pobres ante la capitación universal de 1843, denominada por ellos como el "tributo de blancos", resultó en muertes, el envío del ejército y combates. Como indica con claridad Andrés Guerrero (2002: 33-34, 38), para estas personas, el ser "blancomestizo" (es decir, no ser indígena), les otorgaba un estatus particular que no querían perder, incluyendo para algunos de los que tenían pocos ingresos, el privilegio de evitar el trabajo como peones en las haciendas, que de otra manera hubieran tenido que realizar para poder pagar la capitación.

Los impuestos directos y la reacción del público ante ellos presentan una situación notablemente diferente en Perú, donde la organización fiscal contemplaba, de manera explícita, dos categorías sociales (indígenas y castas) y otra que correspondía a los criollos y mestizos, aun si nunca se formalizó legalmente (Contreras 2005). Estas categorías se definían, finalmente, por los impuestos que se pagaban, pues la categoría de "casta" incluía tanto a "indígenas" que habían logrado afincar ese estatus para reducir su pago

${ }^{37}$ En casi todos los casos, se retomó la periodicidad del sistema colonial de la recaudación del tributo al cobrar la capitación en junio y diciembre, correspondientes a los tercios de San Juan y Navidad.

Araucaria. Revista Iberoamericana de Filosofia, Política y Humanidades, año 18, n 36. Segundo semestre de 2016. Pp. 59-86. ISSN 1575-6823 e-ISSN 2340-2199 doi: 10.12795/araucaria.2016.i36.04 
anual, como también a "blancos" y "mestizos" pobres cuyos pagos para las contribuciones de predios, industria y patentes fueron menores de lo que les habría correspondido por la contribución de castas. Si la resistencia hacia las contribuciones de predios, industria y patentes nunca llegó a provocar su eliminación en Perú, era común que se evitara o rechazara la valoración de los ingresos, creando dificultades para su efectiva implementación y asegurando que su aportación al erario sería de poco importe (Jacobsen 1989: 324, 328).

En el estado de Guatemala, la abolición de la "capitación" fue una de las seis demandas puestas en el manifiesto original de los participantes (indígenas y ladinos) en la Rebelión de la Montaña en 1837, que hizo caer el gobierno liberal y colocó a Rafael Carrera en el poder (Woodward 2002: 88). De manera similar, la resistencia a la contribución directa que se intentó aplicar en Salvador en 1832 provenía tanto de sectores indígenas como de ladinos (Lauria 2003: 173-174). En Chiapas, las Memorias de gobierno de finales de la década de los veinte, además de reiterar una propuesta para una capitación proporcional, dejan entrever que resultaba difícil el cobro de la capitación a (por lo menos algunos) de los no indígenas ${ }^{38}$.

Ante el paso del tributo hacia las contribuciones directas y, en particular a la capitación, la historiografía refiere actitudes divergentes entre los grupos indígenas. A veces esta historiografía indica que los indígenasA veces esta historiografía indica que los indígenas rechazaban las formas iniciales de las contribuciones porque se vinculaban con una posible pérdida del acceso a la tierra, o no realizaban la entrega porque la recaudación a través de funcionarios, en lugar de las autoridades tradicionales, no fue efectiva, o por otras razones. En Yucatán, de manera similar a lo que ocurrió en los Departamentos del Sur de la Gran Colombia, resultó necesario encargar la recaudación de la capitación a las autoridades tradicionales para contrarrestar la ineficacia que habían tenido los subdelegados en sus esfuerzos por cobrar ${ }^{39}$. En los dos casos, el Estado venció la resistencia al pago de la capitación con el restablecimiento (aun si oficialmente con menos prerrogativas) de las autoridades indígenas, lo que demostraba sus propias debilidades administrativas y su incapacidad de mantenerse en pie sin las estructuras comunitarias, heredadas de la colonia, que inicialmente había intentado eliminar. Además, en ambos casos, fueron los funcionarios locales quienes en principio propusieron devolver a las autoridades tradicionales la responsabilidad para la recaudación, aunque en los Departamentos del Sur,

${ }^{38}$ Sobre indicaciones que se deseaba implementar un sistema de cobro graduado, véase Vázquez (2012: 561); "Memoria del estado..." [1826] (2010: f. 11); "Memoria del estado" [1827] (2010: 1011); "Memoria del estado" [1829] (2010: 11); "Memoria del estado" [1830] (2010: 22). Sobre las intimaciones sobre las dificultades para el cobro de los no indígenas, véase "Memoria del estado" [1829)] (2010: 5); "Memoria del estado" [1830] (2010: 19).

${ }^{39}$ Durante la breve duración de la capitación general en los Departamentos del Sur (1826-1828), se había comenzado a utilizar a las autoridades indígenas y a los párrocos para asegurar su cobro efectivo (Morelli 2005:178-179).

Araucaria. Revista Iberoamericana de Filosofía, Política y Humanidades, año 18, n 36. Segundo semestre de 2016. Pp. 59-86. ISSN 1575-6823 e-ISSN 2340-2199 doi: 10.12795/araucaria.2016.i36.04 
tuvo impacto el hecho que los grandes propietarios externaron su preocupación frente a la posibilidad de que el campo se quedara sin trabajadores agrícolas si la capitación no se hacía efectiva. (Van Aken, 1981: 442-443; Palomeque, 1991: 401; Morelli, 2005: 178-179; Güémez 2005: 124; Ortiz Yam 2015).

Entre julio y septiembre de 1824, se restablecieron las "antiguas repúblicas indígenas" en Yucatán, para asegurar el cobro de la capitación (establecida unos pocos meses antes) y para evitar la dispersión de la población. Asimismo, los ayuntamientos se eliminaron -con excepción de los ubicados en las cabeceras de partidos, las ciudades y las villa-y fueron remplazados con juntas municipales que no gozaron - a diferencia de los primeros- de facultades económicas sobre los propios y arbitrios (Ortiz Yam 2015: 215 y 215, n.9). En Ecuador, el restablecimiento del cobro por las autoridades indígenas implicó también el mantenimiento de los cabildos y las tierras comunales que, según lo que Bolívar había decretado en años anteriores, debían dejar de existir ante la creación de los ayuntamientos y la repartición de las tierras (Van Aken 1981: 439; Morelli 2005: 180) ${ }^{40}$.

En Perú, las autoridades republicanas eliminaron a los caciques, cuyo papel desde la Gran Rebelión que revolucionó los Andes en 1780-1781 -bajo los lideratos de Tupac Amaru, Tupac Katari y Tomás Katari en sus respectivas regiones de influencia-, se había reducido al de "cobrador" (cargo ocupado siempre más por mestizos, españoles, o indios desvinculados de la comunidad donde cobraban), y la historiografía no menciona, con algunas excepciones, que los indígenas se negaran a pagar la capitación ${ }^{41}$. La responsabilidad para el cobro parece haber recaído en las autoridades tradicionales de menor rango (los hilacatas, varayocs y alcaldes), los dependientes de los caciques y los mestizos (Hünefeldt 1989: 373-374; Thurner 1997: 37-39), cuya presencia resultaba necesaria por la forma en que se realizaba la recaudación en las comunidades. A pesar de no tener un reconocimiento formal, estas autoridades locales cumplieron con funciones importantes no sólo en la recaudación de la

${ }^{40}$ Al eliminar la capitación general en 1828 y aprobar otra que se aplicara únicamente a los indígenas, se intentó otra vez, sin éxito, transferir la responsabilidad por la recaudación a los funcionarios estatales (Morelli 2005: 181).

41 En el departamento de Puno, en Perú, se rechazó la rebaja de un peso que contemplaba la contribución de indígenas en 1826, al parecer por miedo a que la reducción fuera una trampa (Contreras 2005: 163). En la parte de Ayacucho que se mantuvo bajo el control de los "iquichanos"grupo que incluía no sólo a indígenas sino también curas, mestizos y españoles capitulados, conocido por realista durante las guerras de independencia y notablemente activo en lo militar durante los años posteriores, al punto de controlar un territorio y establecer instituciones durante algunos años (Méndez 2014) - a menudo se rechazaba el pago de la capitación en los años posteriores a la independencia (Méndez 2014: 135, 324 ). En diferentes momentos el grupo rebelde aplicaba un cobro de diezmo que beneficiaba a los peones de las haciendas al insistir que el impuesto se cobraba sobre las ganancias recibidas después de solventar el pago a los trabajadores (Méndez 2014: 249-256, 324). En varias ocasiones los "iquichanos", al igual que otros grupos en Perú en este periodo, rechazaban pagar la capitación con el argumento que habían actuado como soldados en las guerras de la época o bien que habían sufrido mucho en ellas (Méndez 2014: 311-316, 331-345). 
capitación, sino también en la provisión de trabajadores para obras públicas y en las defensas de las prerrogativas comunitarias (Thurner 1997: 37-42).

En los archivos, no se encuentra con facilidad una descripción del proceso de la recaudación del tributo de indios o de las capitaciones republicanas, y raramente se menciona en los estudios publicados. Uno de los pocos ejemplos disponibles que describe el proceso, nos ayuda a entender la importancia de mantener una presencia constante en las comunidades para poder realizar el cobro y asimismo la ineficacia que hubiera tenido un agente externo que llegase una vez cada seis meses: "el cobro de la contribución a los indígenas se hace en todo el trascurso de cada uno de los semestres, pues cediendo a una antiquísima costumbre, los recaudadores subalternos reciben semanalmente cinco, diez o veinte centavos de cada uno de los contribuyentes, demorando así en su cobro cinco meses cuando menos de cada uno de los semestres" (Hünefeldt, 1989: $374)^{42}$.

Las poblaciones indígenas de los estados de Salvador y Guatemala participaron, a menudo como protagonistas, en las protestas y rebeliones que enfrentaron los gobiernos estatales en los años treinta del siglo XIX. En el caso guatemalteco, estas acciones se venían realizando desde por lo menos el periodo gaditano y contribuyeron a las caídas de los gobiernos del estado de Guatemala (1837-1838) y el de Los Altos (1840) (Taracena 1997: 313-324; Woodward 2002: 75-114; Pollack 2013). Asimismo, ante la implementación de una capitación federal a partir de 1840, indígenas en muchos departamentos del centro de México opusieron resistencia (Serrano 2007: 160-161) y, en el departamento de México donde la rebelión (aquí asociada con otros motivos) tuvo más arraigo (Guardino 1996: 147-177; Hernández 2003), lograron, si bien provisionalmente, la aplicación de una exención para los jornaleros y sirvientes que ganaban menos de 300 pesos anualmente (Serrano 2007:161).

En general, sin embargo, se puede considerar que los indígenas en Bolivia, Perú, Ecuador, Yucatán, Chiapas y Oaxaca pagaron la capitación republicana por algunas décadas sin provocar mayores problemas para el fisco ni para los recaudadores $^{43}$. En la zona andina, se ha interpretado, por lo menos en parte, la relativa anuencia de los indígenas hacia la capitación como una muestra de lo que se ha argumentado fue un pacto entre campesinos y gobernantes presente desde la dominación Inca, o incluso pre Inca, en el que el acceso a la tierra dependía del pago de un impuesto (Platt 1982). Sin embargo, como ha

${ }^{42}$ La cita proviene de Perú, pero no incluye el año y la autora refiere a otro caso en el que los pagos en la provincia de Azangaro, Perú se realizaban todos los domingos después de la misa (Hünefeldt 1989: 400, n. 15).

${ }^{43}$ El cobro de la capitación fue uno de los motivos que fomentó la participación indígena en la Guerra de Castas de Yucatán (1848) (Cobá 2009: 276-279) y Rocío Ortiz ha argumentado que los indígenas chiapanecos aceptaron la capitación como mecanismo que - a veces - les permitió conseguir el apoyo del gobierno ante las autoridades eclesiásticas y las obvenciones que solicitaban (Ortiz Herrera 2003).

Araucaria. Revista Iberoamericana de Filosofia, Política y Humanidades, año 18, n⿳ 36. Segundo semestre de 2016. Pp. 59-86. ISSN 1575-6823 e-ISSN 2340-2199 doi: 10.12795/araucaria.2016.i36.04 
argumentado Cecilia Méndez, la existencia de un acuerdo de este tipo en el norte potosino, donde Platt realizó sus investigaciones, no puede ni debe aplicarse a otras regiones andinas que tuvieron experiencias notablemente divergentes (Méndez 2014: 186-187 y 187, n. 4). La fuerza de este quid pro quo, en las regiones donde existiera, seguramente habría aumentado con las políticas de los nuevos gobernantes republicanos que declaraban la abolición del tributo a la vez que proponían la eliminación de las comunidades y de la tierra comunal (Van Aken 1981: 439; Sánchez Albornoz 1978: 203; Peralta 1997: 55) ${ }^{44}$. Por lo mismo, se ha argumentado que la resistencia inicial a las capitaciones en los Departamentos del Sur respondía al deseo de asegurar el mantenimiento de las comunidades y de las autoridades tradicionales (Van Aken 1981: 443), lo que podría pensarse también para el caso yucateco ${ }^{45}$.

Habría que matizar estos argumentos en dos aspectos. En primer lugar, para muchos indígenas propietarios, comerciantes, transportistas y productores para los mercados (Langer 2009), era más conveniente, en términos económicos, pagar una capitación y no las contribuciones directas proporcionales $\mathrm{u}$ otros impuestos como la alcabala interna (Lofstrom 1972: 411; Moscoso 1991: 372; O’Phelan 2011: 422). En segundo lugar, la anuencia al pago en los Departamentos del Sur y Yucatán después del restablecimiento de las autoridades tradicionales debe relacionarse con el interés que ellas habrían tenido en mantener una cuota de poder y, también, en recibir el porcentaje de lo recaudado que les correspondía ${ }^{46}$.

Por otra parte, creo relevante considerar la constitución fiscal vigente: en casi todos los territorios americanos que contaban con una presencia demográfica indígena importante al momento de la eliminación del tributo (entre 1811 y 1825), no había mucha resistencia organizada por parte de los indios hacia su cobro, es decir que este pago se consideraba parte de la economía moral del momento ${ }^{47}$. Así que cuando se eliminó el tributo y -con o sin experimentos impositivos de otra índole en el inter- se estableció una capitación similar, pero menos exigente en términos económicos, no es tan sorpresivo que los indígenas lo aceptasen. La ferocidad de la respuesta a la nueva capitación federal en México en 1842 en los departamentos donde se

${ }^{44}$ Los congresos estatales mexicanos intentaron aplicar leyes de desamortización en la primera mitad del siglo XIX pero tuvieron muy poco éxito antes la aprobación de la Ley Lerdo en 1856 (Silva 2003: 104-106; Torres 2014: 81-87; Arrioja 2014: 493, 493 ns. 11 y 12).

${ }^{45}$ Guarisco (1995: 24) argumenta que en Ecuador las autoridades tradicionales, a diferencia de los funcionarios estatales potencialmente ofrecían a los contribuyentes la posibilidad de ocultarse ante el fisco.

${ }^{46}$ En casi todos los casos donde se implementó una capitación, se aplicaron sistemas similares al que la monarquía había impuesto con el establecimiento de las intendencias en la penúltima década del siglo XVIII en los que un porcentaje de lo recaudado (entre 3\% y 5\%) le correspondía al subdelegado y $1 \%$ a las autoridades indias.

${ }^{47}$ El altiplano guatemalteco es una clara excepción a esta generalización (Fernández 2000; Pollack 2008, 2013).

Araucaria. Revista Iberoamericana de Filosofia, Política y Humanidades, año 18, no 36. Segundo semestre de 2016. Pp. 59-86. ISSN 1575-6823 e-ISSN 2340-2199 doi: 10.12795/araucaria.2016.i36.04 
había dejado de cobrar desde el periodo gaditano contrasta con la aceptación del cobro en Yucatán, Chiapas y Oaxaca donde el nuevo impuesto modificaba muy poco lo que los contribuyentes ya aportaban al fisco.

\section{Para cerrar}

Las constituciones fiscales de Hispanoamérica aseguraron el fracaso de la contribución directa proporcional que los nuevos gobiernos propusieron en la tercera década del siglo diecinueve. Cualquier redistribución de la carga fiscal al interior de cada Estado o provincia habría, necesariamente, requerido que los grupos que habían gozado de privilegios asociados con el sistema estamental en la época anterior aceptaran aportar más a los erarios estatales. Ante esta situación las autoridades retrocedieron en sus intentos redistributivos y optaron por aplicar los impuestos ya conocidos, que no provocaban nuevas inquietudes y facilitaban la estabilidad social. Las contribuciones directas proporcionales que se propusieron habrían implicado (por lo menos el comienzo de) una revolución fiscal (con obvias implicaciones sobre el papel mismo del Estado) la que no podría realizarse sin la presencia de una base social que la apoyara, o un ejército que la impusiera.

Las capitaciones republicanas, a veces en relación con las otras contribuciones directas de la época, se insertaron en las sociedades hispanoamericanas del siglo XIX e influyeron en la modificación de las categorías sociales que se habían heredado del sistema estamental de la colonia. Como impuestos que impactaban -potencial o realmente-de manera más significativa en los indígenas y en los otros grupos sociales con menores ingresos, su desarrollo se entrelazaba con el de las comunidades indígenas y sus variados destinos a lo largo del siglo XIX. Asimismo, su aplicación probablemente haya servido -como también hizo el tributo de indios en los siglos anteriores- a enmascarar las diferentes condiciones económicas al interior de las comunidades. 


\section{Referencias bibliográficas:}

Abendroth, Hans Huber (2006): "La desigual tributación directa en Bolivia, 1825-1872: Indios sí, criollos no" en Luis Jáuregui (coord.), De riqueza e inequidad. El problema de las contribuciones directas en América Latina, siglo XIX, México, Instituto Mora, pp. 79-121.

Alonso García, David (2003): "Carlos V, Madrid y el sistema fiscal castellano", Revista de Historia Económica, año XXI, primavera-verano, núm. 2, pp. 271-295.

Arrioja Díaz Viruell, Luis Alberto (2014): "Pueblos, reformas y desfases en el sur de México: Oaxaca, 1856-1857”, Historia Mexicana, vol. LXIV, núm. 2, pp. 487-532.

Barahona, Marvin (1995), "Honduras. El estado fragmentado (1839-1876)" en Jean Piel y Arturo Taracena (coords.), Identidades nacionales y Estado moderno en Centroamérica, San José, Centro de Estudios Mexicanos y Centroamericanos/FLACSO El Salvador/Editorial de la Universidad de Costa Rica, pp. 97-114.

Barragán, Rossana (2012): "Los títulos de la corona de España de los indígenas: para una historia de las representaciones políticas, presiones y negociaciones entre Cádiz y la república liberal”, Boletín Americanista, año LXII (2), núm. 65, pp. 15-37.

Bonilla, Heraclio (1991): "Estado y tributo campesino. La experiencia de Ayacucho" en Heraclio Bonilla (comp.), Los Andes en la Encrucijada. Indios, Comunidades y Estado en el siglo XIX, Quito, Ediciones Libri Mundi, Enrique Grosse-Luemern, FLACSO-Ecuador, pp. 335 - 366.

Bonilla, Heraclio (1997): "Estructura y articulación política de las comunidades indígenas de los Andes centrales con sus Estados nacionales" en Leticia Reina (coord.), La reindianización de América, Siglo XIX, México, Siglo XXI/CIESAS, pp. 93-108.

Bonney, Richard (ed.) (1995a): Economic systems and state finance, Oxford, Clarendon Press.

Bonney, Richard (1995b): "Introduction”, en Richard Bonney (ed.), Economic systems and state finance, Oxford, Clarendon Press, pp. 1-18.

Bonney, Richard (1995c): "Revenues", en Richard Bonney (ed.), Economic systems and state finance, Oxford, Clarendon Press, pp. 423-505.

Brennan, Geoffrey and James M. Buchanan (2000): The Power to Tax: Analytical Foundations of a Fiscal Constitution, Indianapolis, Liberty Fund.

Bushnell, David (1999): "The Indian Policy of Jujuy Province, 1835-1853", The Americas, vol. 55, núm. 4, pp. 579-600. 
Cobá Noh, Lorgio (2009): El “indio Ciudadano". La tributación y la contribución personal directa en Yucatán, 1786-1825, México, Instituto Mora.

Contreras, Carlos (1989): "Estado republicano y tributo indígena en la Sierra Central en la Post-Independencia", Histórica, vol. XIII, núm. 1, pp. 9-44.

Contreras, Carlos (2005): "El impuesto de la contribución personal en el Perú del siglo XIX”, Histórica, vol. 29, núm. 2, pp. 67-106.

Coria, Luis A. (1998): "Las finanzas provinciales en tiempos de Rosa", Anales de la AAEP, [en línea] www.aaep.org.ar/anales/works/works1998/CORIA. PDF [consultado el 20 de febrero de 2016].

Dancuart , P. Emilio y J. M. Rodríguez (eds.) (1902-1926), Anales de la hacienda pública del Perú, 24 vols., Lima. vol. III.

Daunton, Martin (2001): Trusting Leviathan: The Politics of Taxation in Britain, 1799-1914, Cambridge, Cambridge University Press.

"Decreto que establece la contribución personal de indígenas", 15 de octubre de 1828, Codificación Nacional de todas las leyes de Colombia desde el año de 1821, tomo III, Años de 1827 y 1828, Bogotá, Imprenta Nacional, 1925, pp. 420-426.

"Decreto que ordena ejecutar fielmente las leyes de hacienda", 23 de noviembre de 1826, Codificación Nacional de todas las leyes de Colombia desde el año 1821.Tomo II, Años de 1825 y 1826, Bogotá, Imprenta Nacional, 1924, pp. 413-414.

"Decreto sobre contribución directa”, 21 de agosto de 1832, Ministerio general del gobierno del Estado del Salvador, Colección de decretos y órdenes de la Asamblea y Gobierno del Estado correspondiente a los años de 1831 y 1832, San Salvador, Imprenta del Estado, s/f, pp. 69-75.

Escobar Ohmstede, Antonio (2010): "Del dualismo étnico colonial a los intentos de homogeneidad en los primeros años del siglo XIX latinoamericano" en Antonio Escobar Ohmstede, Romana Falcón Vega y Raymond Buve (coords.), La arquitectura histórica del poder. Naciones, nacionalismos y estados en América Latina. Siglos XVIII, XIX y XX, México, El Colegio de México/CEDLA, pp. 41-57.

Etchechury Barrera, Mario (2013): "Hijos de Mercurio, esclavos de Marte. Mercaderes y Servidores del Estado en una frontera sud-Atlántica, Montevideo, 1806-1860", tesis de doctorado, Departament d'Humanitats, Barcelona, Universitat Pompeu Fabra.

Fernández Molina, Manuel (2000): Los tributos en el reino de Guatemala: 1786-1821, 2a. ed., Guatemala, Universidad de San Carlos de Guatemala. Garavaglia, Juan Carlos (2010): "Algunos aspectos preliminares acerca de la 'transición fiscal' en América Latina: 1800-1850”, Illes i Imperis, núm. 13, pp. 159-192. 
Gelman, Jorge y Daniel Santilli (2006): "Entre la eficiencia y la equidad. Los desafíos de la reforma fiscal en Buenos Aires. Primera mitad del siglo XIX”, Revista de Historia Económica, segunda época, vol. XXIV, núm. 3, pp. 491-520.

Gross, Jean-Pierre (1993): "Progressive Taxation and Social Justice in Eighteenth Century France", Past and Present, núm. 140, pp. 79-126.

Guardino, Peter (1996): Peasants, Politics, and the Formation of Mexico's National State: Guerrero, 1800-1857, Stanford, Stanford University Press. Guarisco, Claudia (1995): "Entre la obediencia y la evasión. El tributo indígena en el Ecuador del siglo XIX”, Allpanchis phuturinqa, núm. 46, pp. 11-43.

Guarisco, Claudia (2003): "Etnicidad y ciudadanía: los orígenes de un problema. El caso del Valle de México (1812-1835)", Revista de Historia de América, núm. 133, pp. 9-44.

Güémez Pineda, Arturo (2005): Mayas. Gobierno y tierras frente a la acometida liberal en Yucatán, 1812-1847, Zamora, El Colegio de Michoacán/ Universidad Autónoma de Yucatán.

Guerrero, Andrés (2002): "El proceso de identificación: sentido común ciudadano, ventriloquia y transescritura" en Antonio Escobar Ohmstede, Romana Falcón y Raymond Buve (comps.), Pueblos, comunidades y municipios frente a los proyectos modernizadores en América Latina, siglo XIX, San Luis Potosí, Colegio de San Luis/CEDLA, pp. 29-63,

Guerrero, Andrés (2010): Administración de poblaciones, ventriloquía y transescritura. Análisis históricos, estudios teóricos, Lima, Instituto de Estudios Peruanos/FLACSO Sede Ecuador.

Guery, Alain (1986): "État, classification sociale et compromis sous Louis XIV: la capitation de 1695", Annales. Histoire, Sciences Sociales, 41 Année, núm. 5, pp. 1041-1060.

Hernández Jaimes, Jesús (2003): “Actores indios y Estado nacional: Las rebeliones en el sur de México, 1842-1846, Estudios de Historia Moderna y Contemporánea de México, núm. 26, pp. 5-44.

Hernández Jaimes, Jesús (2013): La formación de la Hacienda pública mexicana y las tensiones centro-periferia, 1821-1835, México, El Colegio de México/Instituto Mora/UNAM.

Herrera Mena, Sajid Alfredo (2008): "Fiscalidad, estancos y federación: los termómetros de la fortaleza gubernamental en El Salvador (1824-1839)" en Los estancos, las prácticas monopólicas y las rentas del Estado en El Salvador, San Salvador, Superintendencia de Competencia de El Salvador, pp. 69-75.

Hünefeldt, Christine (1989): "Poder y contribuciones: Puno, 1824-1845", Revista Andina, vol. 7, núm. 2, pp. 367-407. 
Hünefeldt, Christine (1991): "Circulación y estructura tributaria: Puno 18401890” en Enrique Urbano (comp.), Poder y violencia en los Andes, Cusco, Centro de Estudios Regionales Andinos Bartolomé de Las Casas, pp. 189210.

Ibarra, Antonio (1998): "Reforma y fiscalidad republican en Jalisco: Ingresos estatales, contribuciones directas y pacto federal, 1824-1835" en José Antonio Serrano Ortega y Luis Jáuregui (eds.), Hacienda y política. Las finanzas públicas y los grupos de poder en la primera República Federal Mexicana, México, El Colegio de Michoacán/Instituto Mora, pp. 133-174.

Ibarra, Antonio (2001): "De la alcabala colonial a la contribución directa republicana. Cambio institucional y continuidad fiscal en una economía regional mexicana, Guadalajara 1778-1834” en Ernest Sánchez Santiró, Luis Jáuregui y Antonio Ibarra (coords.), Finanzas y política en el mundo iberoamericano. Del antiguo régimen a las naciones independientes, México, Universidad Autónoma del Estado de Morelos/Instituto Mora/ Facultad de Economía-UNAM, pp. 317-350.

Irurozqui Victoriano, Marta (1999): "Las paradojas de la tributación. Ciudadanía y política estatal indígena en Bolivia, 1825-1900”, Revista de Indias, vol. LIX, núm. 217, pp. 705-740.

Irurozqui Victoriano, Marta (2006): "Sobre el tributo y otros atributos ciudadanos: sufragio censitario, fiscalidad y comunidades indias en Bolivia, 1825-1839”, Bicentenario. Revista de Historia de Chile y América, vol. 5, núm. 2, pp. 35-66.

Jacobsen, Nils (1989): "Taxation in Early Peru, 1821-1851: Policy Making Between Reform and Tradition" en Reinhard Liehr (ed.), América Latina en la época de Simón Bolivar. La formación de las economías nacionales y los intereses económicos europeos, 1800-1850, Berlino, Colloquium Verlag, pp. 311-339.

Jáuregui, Luis (2006a): “De re tributaria ¿Qué son las contribuciones directas?” en Luis Jáuregui (coord.), De riqueza e inequidad. El problema de las contribuciones directas en América Latina, siglo XIX, México, Instituto Mora, pp. 9-45.

Jáuregui, Luis (coord.) (2006b): De riqueza e inequidad. El problema de las contribuciones directas en América Latina, siglo XIX, México, Instituto Mora.

Klein, Herbert S. (1995): Haciendas y ayllus en Bolivia, ss. XVIII y XIX, Lima, Instituto de Estudios Peruanos, traducido del inglés por Javier Flores.

Kwass, Michael (1998): “A Kingdom of Taxpayers: State Formation, Privilege, and Political Culture in Eighteenth Century France", The Journal of Modern History, vol. 70, núm. 2, pp. 295-339. 
Langer, Erick D. (2009): "Bringing the Economic Back In: Andean Indians and the Construction of the Nation-State in Nineteenth-Century Bolivia", Journal of Latin American Studies, vol. 41, núm. 3, pp. 527-551.

Lauria Santiago, Aldo (2003): Una república agraria. Los campesinos en la economía y la política de El Salvador en el siglo XIX, trad. de Márgara Zablah de Sumán, San Salvador, Consejo Nacional para la Cultura y el Arte.

Lofstrom, William (1970): “Attempted Economic Reform and Innovation in Bolivia under Antonio José de Sucre, 1825-1828”, The Hispanic American Historical Review, vol. 50, núm. 2, pp. 279-299.

Lofstrom, William Lee (1972): "The Promise and Problem of Reform: Attempted Social and Economic Change in the First Years of Bolivian Independence", Tesis de doctorado, Graduate School of Cornell University, Ithaca, NY.

López Castellano, (1995): El liberalismo económico y reforma fiscal. La contribución directa de 1813, Granada, Universidad de Granada/ Fundación Caja de Granada.

López Taverne, Elvira (2014): "La política fiscal en Chile. Configuración y problemáticas de las Hacienda pública en el marco del proceso de construcción estatal", Amérique Latine Histoire \& Memoire. Les Cahiers (ALHIM), núm. 28, [en línea], http://alhim.revues.org/5008 [consultado el 13 de febrero, 2016].

Marure, Alejandro (1844): Efemérides de los hechos notables acaecidos en la Republica de Centro-América desde el año de 1821 hasta el de 1842, Guatemala, Ministerio de Educación Pública.

"Memoria del Estado actual en que se hallan los ramos de la administracion publica de las Chiapas" (1826), Ciudad Real, 12 de febrero de 1827 en Julius Fenner, Memorias e Informes de los Gobernadores de Chiapas, 1826-1900 [CD-ROM], Tuxtla Gutiérrez, UNICACH/Archivo Histórico de Chiapas/UNAM/IA/ PROIMMSE, 2010.

"Memoria del estado actual en que se hallan los ramos de la administracion publica de las Chiapas" (1827), Capital de Chiapas, Imprenta de la Sociedad, 6 de febrero de 1828 en Julius Fenner, Memorias e Informes de los Gobernadores de Chiapas, 1826-1900 [CD-ROM], Tuxtla Gutiérrez, UNICACH/Archivo Histórico de Chiapas/UNAM/IA/PROIMMSE, 2010.

"Memoria del estado en que se hallan los ramos de la administracion publica de las Chiapas" (1829), San Cristoval, Imprenta de la Sociedad, 20 de febrero de 1830, en Julius Fenner, Memorias e Informes de los Gobernadores de Chiapas, 1826-1900 [CD-ROM], Tuxtla Gutiérrez, UNICACH/Archivo Histórico de Chiapas/UNAM/IA/PROIMMSE, 2010. 
"Memoria del estado en que se hallan los ramos de la administracion publica de las Chiapas", (1830), San Cristoval, Imprenta de la Sociedad, 10 de febrero de 1831, en Julius Fenner, Memorias e Informes de los Gobernadores de Chiapas, 1826-1900 [CD-ROM], Tuxtla Gutiérrez, UNICACH/Archivo Histórico de Chiapas/ UNAM/IA/PROIMMSE, 2010.

Méndez Gastelumendi, Cecilia (1997): "Pactos sin tributo. Caudillos y campesinos en el Perú postindependiente: el caso de Ayacucho" en Leticia Reina (coord.), La reindianización de América, Siglo XIX, México, Siglo XXI/CIESAS, pp. 161-185.

Méndez Gastelmundi, Cecilia (2014): La república plebeya. Huanta y la formación del Estado peruano, 1820-1830, Lima, Instituto de Estudios Peruanos.

Menegus Bornemann, Margarita (1998): "Alcabala o tributo. Los indios y el fisco (siglos XVI al XIX). Una encrucijada fiscal” en Luis Jáuregui y José Antonio Serrano Ortega (coords.), Las finanzas públicas en los siglos XVIIIXIX, México, Instituto Mora, pp. 110-130.

Morelli, Federica (2005): Territorio o nación. Reforma y disolución del espacio imperial en Ecuador, 1765-1830, trad. del francés por Antonio Hermosa Andujar, Madrid, Centro de Estudios Políticos y Constitucionales.

Moreno Acevedo, Elda (2014): "Riqueza e impuestos: el nacimiento de la Hacienda pública en Yucatán (1821-1825)”, Revista de Historia, núm. 69, pp. 29-40.

Moscoso, Martha (1991): "La tierra: espacio de conflicto y relación entre el Estado y la comunidad en el siglo XIX" en Heraclio Bonilla (comp.), Los Andes en la Encrucijada. Indios, Comunidades y Estado en el siglo XIX, Quito, Ediciones Libri Mundi, Enrique Grosse-Luemern, FLACSOEcuador, pp. 367-390.

O’Brien, Patrick K. (1988): "The political economy of British taxation, 16601815”, The Economic History Review, 2a. serie, vol. 41, núm. 1, pp. 1-32.

O'Brien, Patrick K. (2011): "The nature and historical evolution of an exceptional fiscal state and its possible significance for the precocious commercialization and industrialization of the British economy from Cromwell to Nelson", The Economic History Review, vol. 64, núm. 2, pp. 408-446.

O'Phelan Godoy, Scarlett (2011): “Presentación", Anuarios de Estudios Americanos, vol. 68, núm.2, Sevilla, pp. 415-427.

Ortíz Herrera, Rocío (2003): Pueblos indios, iglesia católica y élites politicas en Chiapas, 1824-1901. Una perspectiva comparativa. Tuxtla Gutiérrez, Gobierno del estado de Chiapas, 2003.

Ortiz Yam, Inés (2015): “Exacción y vigilancia. Las repúblicas indígenas del régimen liberal” en Antonio Escobar Ohmstede, José Marcos Medina 
Bustos, Zulema Trejo Contreras (Coords.), Los efectos del liberalismo en México: Siglo XIX, México, El Colegio de Sonora/CIESAS, pp. 207-232.

Palomeque, Silvia (1991): "Estado y comunidad en la región de Cuenca en el siglo XIX. Las autoridades indígenas y su relación con el Estado" en Heraclio Bonilla (comp.), Los Andes en la Encrucijada. Indios, Comunidades y Estado en el siglo XIX, Quito, Ediciones Libri Mundi/ Enrique Grosse -Luemern/FLACSO-Ecuador, pp. 391- 417.

Peralta Ruíz, Víctor (1991): En pos del tributo. Burocracia estatal, elite regional y comunidades indígenas en el Cusco rural 1826-1854, Cusco, Centro de Estudios Regionales Andinos Bartolomé de Las Casas.

Peralta Ruiz, Víctor (1997): "Comunidades, hacendados y burócratas en el Cusco (Perú), 1826-1854” en Leticia Reina (coord.), La reindianización de América, Siglo XIX, México, Siglo XXI/CIESAS, pp. 53-69.

Pinto Bernal, Joaquín (2012): "Los orígenes del impuesto directo y progresivo en América Latina", Historia y Sociedad, núm. 23, pp. 53-77.

Platt, Tristan (1982): Estado boliviano y ayllu andino: tierra y tributo en el norte de Potosí, Lima, Instituto de Estudios Peruanos.

Pollack, Aaron (2008): Levantamiento K’iche’ en Totonicapán, 1820. Los lugares de las politicas subalternas, Guatemala, Asociación para el Avance de las Ciencias Sociales en Guatemala (AVANCSO), 2008.

Pollack, Aaron (2013): “Totonicapán, 1820, ¿Uno de los puntos del iceberg?" en Aaron Pollack (coord.), La época de las independencias en Centroamérica y Chiapas: procesos políticos y sociales, México, Instituto Mora/Universidad Autónoma Metropolitana (UAM)-Iztapalapa, 2013.

Pollack, Aaron (2016): "Hacia una historia social del tributo de indios y castas en Hispanoamérica. Notas en torno a su creación, desarrollo y abolición" Historia Mexicana, México, El Colegio de México, vol. LXVI, núm. 1, pp. 65-160.

Rodríguez Solano, Pablo Augusto (2013): "Cambios y continuidad: La hacienda pública como factor de construcción estatal, Costa Rica 18121859", tesis de doctorado del Departamento de Humanidades, Universitat Pompeu Fabra, Barcelona, 2013.

Sánchez Albornoz, Nicolás (1978): Indios y tributos en el Alto Perú, Lima, Instituto de Estudios Peruanos, 1978.

Sánchez Santiró, Ernest (2012): "La irrupción del liberalismo fiscal en Nueva España: La contribución directa general y extraordinaria (1813-1815)", América Latina en la Historia Económica, vol. 19, núm. 1, pp. 9-35.

Sánchez Silva, Carlos (1998): Indios, comerciantes y burocracia en la Oaxaca poscolonial, 1786-1860, Oaxaca, Instituto Oaxaqueño de las Culturas/ Fondo Estatal para la Cultura y las Artes/Universidad Autónoma Benito Juárez de Oaxaca. 
Sánchez Silva, Carlos (2012): "De la 'unidad' federalista a la 'disidencia' centralista en Oaxaca, 1825-1835" en Josefina Zoraida Vázquez y José Antonio Serano Ortega (coords.), Práctica y fracaso del primer federalismo mexicano (1824-1835), México, El Colegio de México, pp. 291-323.

Sarazúa Pérez, Juan Carlos (2012): "Finanzas estatales en Guatemala, 18231850” en David Díaz Arias y Ronny Viales Hurtado (eds.), Independencias, Estados y Política(s) en la Centroamérica del Siglo XIX. Las Huellas Históricas del Bicentenario, San José, Universidad de Costa Rica, pp. 6587.

Sarazúa Pérez, Juan Carlos (2013): “Recolectar, administrar y defender: la construcción del Estado y las resistencia regionales en Guatemala, 18001871", tesis de doctorado en Historia, Barcelona, Universitat Pompeu Fabra.

Seligman, Edwin (1894): "Progressive Taxation in Theory and Practice", Publications of the American Economic Association, vol. 9, núm. 1/2, pp. 7-222.

Serrano Ortega, José Antonio (2007): Igualdad, uniformidad, proporcionalidad. Contribuciones directas y reformas fiscales en México, 1810-1846, El Colegio de Michoacán/Instituto Mora.

Silva Prada, Natalia (2003): "Las manifestaciones políticas indígenas ante el proceso de control y privatización de tierras: México, 1786-1856" en Brian Connaughton (coord.), Poder y legitimidad en México en el siglo XIX. Instituciones y cultura política, México, UAM-Iztapalapa/Miguel Ángel Porrúa, pp. 75-135.

Storrs, Christopher (2009): "Introduction: The Fiscal-Military State in the 'Long' Eighteenth Century”, en Christopher Storrs (ed.), The Fiscal Military State in Eighteenth Century European polities, Princeton, NJ, Princeton University Press, pp. 1-22.

Taracena Arriola, Arturo (1997): Invención criolla, sueño ladino, pesadilla indigena. Los Altos de Guatemala: de región a Estado, 1740-1850, San José, Editorial Porvenir/Centro de Investigaciones Regionales de Mesoamérica.

Taracena Arriola, Arturo con la colaboración de Gisela Gellert, Enrique Gordillo Castillo, Tania Sagastume Paiz y Knut Walter (2002): Etnicidad, estado y nación en Guatemala, 1808-1944, vol.1, Guatemala, CIRMA.

Tenenbaum, Barbara A. (1998): "Sistema tributario y tiranía: Las finanzas públicas durante el régimen de Iturbide, 1821-1823” en Luis Jáuregui y José Antonio Serrano Ortega (coords.), Las finanzas públicas en los siglos XVIII-XIX, México, Instituto Mora, pp. 209-226. 
Thurner, Mark (1997): From Two Republics to One Divided: Contradictions of Postcolonial Nationmaking in Andean Peru, Durham, Duke University Press.

Torres Freyermuth, Amanda Ursula (2014): “Los 'hombres de bien' en Chiapas, 1809-1835. Un estudio de la élite política a través de las redes sociales", tesis de doctorado en Historia, UAM-Iztapalapa.

Trens, Manuel B. (1999): Historia de Chiapas. Desde los tiempos más remotos hasta la caída del Segundo Imperio (¿...1867?), Tuxtla Gutiérrez, Consejo Estatal para la Cultura y las Artes de Chiapas, vol. II.

Van Aken, Mark (1981): "The Lingering Death of Indian Tribute in Ecuador", The Hispanic American Historical Review, vol. 61, núm. 3, pp. 429-459.

Vázquez Olivera, Mario (2012): "El confín de la república. Chiapas y la primera república federal, 1824-1835" en Josefina Zoraida Vázquez y José Antonio Serano Ortega (coords.), Práctica y fracaso del primer federalismo mexicano (1824-1835), México, El Colegio de México, pp. 545-574.

Woodward, Ralph Lee Jr. (2001): Rafael Carrera y la creación de la Republica de Guatemala, 1821-1871, South Woodstock, Vermont, Plumsock Mesoamerican Studies. 